\title{
End of Transportation of Spent Laying Hens: From Idea to Solution
}

\author{
Avi Pinkas \\ HAI-MESHEK-The Israeli Society for the Prevention of Cruelty to Farm Animals, NGO 8 Geulimst, Rishon Le-Zion, Israel
}

\begin{abstract}
Transportation of spent laying hens causes them severe suffering. HAI-MESHEK (The Israeli Society for the Prevention of Cruelty to Farm Animals) looked for ways to decrease the suffering and finally developed the solution. Spent laying hens are brutally taken out of the cages, and with broken legs and chests pressed into small boxes for transportation to the slaughter-house. Removing all hens from the cages, transportation, waiting in the slaughter-house and slaughtering all hens is a long and hard-suffering time, which may take 8-10 hours. Hai-Meshek conducted a research, aimed at finding more humane methods of transportation. The findings from other countries were very disappointing. Even in countries having high level of animal welfare, about $30 \%$ of the hens arrived at the slaughter-house with broken limbs! The conclusion was that even better method, imposed by legislation, would not solve the problem: it is difficult to detect truck drivers violating the rules and the fine is negligible, compared to the savings by the abovementioned cruel method. The only humane solution is by preventing the transportation and slaughtering on farm. Spent laying hens are not edible, so they need not be slaughtered in the slaughter-house. Hai-Meshek initiated and participated in the development and the building of a facility for the humane killing of spent laying hens on farms. The hens are electrified and die in 1-1.5 seconds. This method costs far less than transportation and slaughtering. The Poultry Council, which takes care to remove spent laying hens from farms, requires contractors to use the facility and they bring it to every farm in Israel. The facility is also used for killing sick flocks. No more transportation of spent laying hens is allowed!
\end{abstract}

Key words: Spent laying hens, humane killing, kosher slaughter, farm animals’ welfare, stunning, transportation of spent hens, killing sick flocks.

\section{The Research}

HAI-MESHEK (The Israeli Society for the Prevention of Cruelty to Farm Animals) conducted a research, by Sharon Shvarts, August 1996, aimed to find how spent laying hens are being treated in Israel, starting their removal from the cages, during transportation and at the slaughter-house. In case of unsatisfactory welfare, it reviews treatment in other countries, in order to find the most humane treatment that can be applied in Israel.

The research found that transportation of spent laying hens causes them terrible suffering. They are removed from the cages by unskilled workers, whose only motivation is to finish the work as soon as possible. This is the only instruction they receive from

Corresponding author: Avi Pinkas, B.Sc. Eng., M.A. Ed., chairman. their foreman, who does not care about animal welfare.

The worker catches the hens by the leg or wing or head and pulls them out from the cage. By doing so, in many cases he breaks their limbs, causing the hens severe pains.

In such conditions the hens suffer for many hours: the time it takes to remove all hens, transport them to the slaughter-house and slaughtering all hens, may take up to 10 hours.

Broilers are handled more gently. According to the Halaha - the Jewish religious rules, it is forbidden to slaughter an animal or bird who has broken limbs. It is not kosher-not edible. Broilers are transported in better condition: 8 hens in a cage, while spent laying hens are squashed up to 14 in each cage!

The findings from other countries were very disappointing. Even in countries having high level of 
animal welfare, about $30 \%$ of the hens arrived at the slaughter-house with broken limbs!

The idea of legislation was examined and rejected for several reasons:

(1) It may take many years and no one can assure the results.

(2) It is nearly impossible to catch the law breaker and the chance to receive budget for such action is very small.

(3) Punishments by court are ridiculous taxes and it will take no more than two days of transporting the same cruel way, to earn back the tax money.

The conclusion of our research was: the only way to end the suffering during transportation is by eliminating the transportation and killing the hens on farm.

Someone already made attempt to imply this concept. Spent hens are not edible, so they must not be Kosher slaughtered. A movable facility for slaughter on farm was built, but the project failed. The farmers and their neighbors rejected this solution because of the hen's screaming and the spread of blood. In addition, the hens suffered from the slaughtering because it was without stunning.

\section{The Solution}

Hai-Meshek decided to develop a facility which will kill the hens momentarily, by electrical shock. Implementing this idea was quite complicate.

\subsection{Producer}

The first step was finding a producer, experienced in facility development. However, this was the easier part of the project. We had a very good experience with the MARD (Research and Development Department of the Ministry of Agriculture).

They developed, according to our specifications, a facility for electrocution of one day male chicks.

\subsection{Project budget}

The above-mentioned experience with MARD helped both parties to prepare the project budget.

\subsection{Funding}

The most difficult part was to rise the funding for the project. Applications to relevant donators were fruitless. The only possibility was to apply to the Poultry Council, which is responsible for the transport of spent laying hens to the slaughter house. It took 3 years to convince them to allocate some money for the project.

\subsection{Approval}

Before starting development we needed the approval of two persons:

(1) The veterinarian in charge of poultry health.

(2) The veterinarian in charge of implementing the Animal Welfare Law.

Our past experience with both of them was very bad. Killing of one-day-old male chick was in very cruel and long-lasting methods. Our suggestions to hatcheries to use more humane methods: by gas or by high speed rotating facilities, were rejected. To solve this problem, we initiated the development of a facility which killed the chicks in one second. We started the development without asking approval from the above-mentioned veterinarians and paid a very high price for it.

This time we asked for the approval before starting development and had no problems.

\subsection{The Development}

Several months after the development started it ceased because the Poultry Council spread the funding over 3 years. But then something unexpected happened. Someone, with hidden camera, filmed the abuse in the hen's transportation. The film was projected on TV prime-time and caused strong public protest. This forced the Council to allocate all funding immediately. The prototype was successfully completed in few months. The electrical current passes from the hen's head to its legs, so both brain 
and heart are affected. Hens die in approximately 1 second.

From the year 2004 every contractor is required to use this facility. Transportation of dead hens reduces transportation costs and eliminates slaughtering at the slaughter-house. Thus the facility both improves hen's welfare and reduces costs.

\section{Discussion}

Hai-Meshek conducted several researches, aimed at finding ways to improve Farm Animals Welfare. The first step was always to search for solutions in other countries and, if satisfactory, to try to implement them. For example, minimum suffering in killing of one day old male chicks. Both solutions, used around the world, were rejected by local hatcheries. HAI-MESHEK had to develop a third solution-the electrocution facility which kills the chick in one second.

In case of transportation of spent laying hens, we did not find solutions, minimizing the suffering, so had to create the abovementioned solution.

The preferred solutions were always those which farmers, their organizations and the Ministry of Agriculture will accept willingly. This was not always possible, as in the case of Force Feeding of Geese prohibition. In this case several farmers lost their income.

There was some resistance to the "one day old chick's electrocution”, because of some additional expenses.

But even in case of the "Killing on Farm Facility", which saved a lot of money from transportation in cages and slaughtering in slaughterhouse, the Poultry Council hesitated three years before joining the project.

The recent project of HAI-MESHEK is "Hens from Cages to Free Range”.

The Ministry of Agriculture insists farmers will replace the old Battery Cages with new ones. Farmers refuse, because of the very high cost. Hai-Meshek insists the new facilities should all be Free Range. The Knesset and the High Court of Justice are involved, too. All parties fight each against the others, instead of considering the "WIN-WIN" suggestion of HAI-MESHEK, which is good for all parties. It will take time, but this, we believe, will be the solution.

\section{Conclusions: Additional Use and Further Development}

\subsection{Sick Flocks}

The facility can also be used for more humane killing of sick flocks.

\subsection{Dry Stunning}

In an experiment it was found that hens may be only stunned by lowering the voltage. With some adaptations the facility can be used for dry stunning before slaughtering of broilers.

\subsection{Kosher Slaughtering}

According to the Jewish Kosher Laws, it is prohibited to slaughter a dead animal or an animal which has broken organs. In the experiment it was found that:

(1) All hens were only stunned and no one died.

(2) No organ, including head and legs, was broken or damaged.

So the facility, after adaptation, can be used for Kosher slaughtering and may resolve the conflict between Kosher Demands and Broiler Welfare.

Follows a link to a short film, showing the facility in work: https://youtu.be/tordBZqXj2s.

\section{References}

[1] Freeman, B. M. 1984. “Transport of Poultry.” WPSA J 40: 19-30.

[2] Mitchell, M. A., and Kettlewell, P. J. 1994. "Road Transportation of Broiler Chickens: Induction of Physiological Stress.” WPSA J 50: 57-9.

[3] Mitchell, M. A., and Kettlewell, P. J. 1994. "Catching Handling \& Loading of Poultry for Road Transportation.” WPSA J 50: 54-6. 
[4] Baker, C. J. 1994. "Aerodynamics of Poultry Transporters: Implication for Environmental Control.” WPSA J 50: 62-3.

[5] Randall, J. M., Streader, W. V., and Meehan, A. M. 1994. "Vibration on Poultry Transport.” WPSA J 50: 64-5.

[6] Gregory, N. G. 1994. "Pathology and Handling of Poultry at the Slaughterhouse.” WPSA J 50: 66-7.

[7] Scott, G. B. 1994. "Poultry Handling: A Review of Mechanical Devices and Their Effect on Bird Welfare.” WPSA J 50: 44-57.

[8] Knowles, T. G., and Broom, D. M. 1990. "Handling and Transport of Broilers and Spent Hens.” Applied Animal
Behavior Science 28: 75-91.

[9] Raj, A. B. M. 1994. "An Investigation into the Batch Killing of Turkeys in Their Transport Containers." British Vet. Association 56 (3): 325-31.

[10] Kettlewell, R. G., and Hallworth, R. N. 1990. "Electrical Stunning of Chickens.” J. Agri. Res. 47: 139-51.

[11] Poole, G. H., and Fletcher, D. L. 1995. “A Comparison of Argon, Carbon-Dioxide, and Nitrogen in a Broiler Killing System.” Poultry Science 74: 1218-23.

[12] Kondaiah, N., and Panda, B. 1992. "Processing and Utilization of Spent Hens.” World Poultry Science Journal 48: 255-67. 